Old Dominion University

ODU Digital Commons

CCPO Publications

Center for Coastal Physical Oceanography

2007

\title{
Simulations of Phytoplankton Species and Carbon Production in the Equatorial Pacific Ocean 2. Effects of Physical and Biogeochemical Processes
}

Baris Salihoglu

Eileen E. Hofmann

Old Dominion University, ehofmann@odu.edu

Follow this and additional works at: https://digitalcommons.odu.edu/ccpo_pubs

Part of the Biogeochemistry Commons, and the Oceanography Commons

\section{Repository Citation}

Salihoglu, Baris and Hofmann, Eileen E., "Simulations of Phytoplankton Species and Carbon Production in the Equatorial Pacific Ocean 2. Effects of Physical and Biogeochemical Processes" (2007). CCPO Publications. 75.

https://digitalcommons.odu.edu/ccpo_pubs/75

\section{Original Publication Citation}

Salihoglu, B., \& Hofmann, E.E. (2007). Simulations of phytoplankton species and carbon production in the equatorial Pacific Ocean 2. Effects of physical and biogeochemical processes. Journal of Marine Research, 65(2), 275-300.

This Article is brought to you for free and open access by the Center for Coastal Physical Oceanography at ODU Digital Commons. It has been accepted for inclusion in CCPO Publications by an authorized administrator of ODU Digital Commons. For more information, please contact digitalcommons@odu.edu. 


\title{
Simulations of phytoplankton species and carbon production in the equatorial Pacific Ocean 2. Effects of physical and biogeochemical processes
}

\author{
by Baris Salihoglu ${ }^{1,2,3}$ and Eileen E. Hofmann ${ }^{1}$
}

\begin{abstract}
A one-dimensional multi-component lower trophic level ecosystem model that includes detailed algal physiology is used to investigate the response of phytoplankton community and carbon production and export to variations in physical and biochemical processes in the Cold Tongue region of the equatorial Pacific Ocean at $0 \mathrm{~N}, 140 \mathrm{~W}$. Results show that high-frequency variability in vertical advection and temperature is an important mechanism driving the carbon export. Filtering out low frequency physical forcing results in a $30 \%$ increase in primary production and dominance of high-light adapted Prochlorococcus and autotrophic eukaryotes. Sensitivity studies show that iron availability is the primary control on carbon export and production; whereas, algal biomass concentration is largely regulated by zooplankton grazing. Recycled iron is an important component of the ecosystem dynamics because sustained growth of algal groups depends on remineralized iron which accounts for $40 \%$ of the annual primary production in the Cold Tongue region. Sensitivity studies show that although all algal groups have a considerable effect on simulated phytoplankton carbon biomass, not all have a strong effect on primary production and carbon export. Thus, these sensitivity studies indicate that it may not be necessary to represent a broad spectrum of algal groups in carbon cycle models, because a few key groups appear to have a large influence on primary production and export variability. Combining the low-light adapted Prochlorococcus, high-light adapted Prochlorococcus and Synechococcus groups as a single group and using a three algal group model may be sufficient to simulate primary production and export variability in the tropical Pacific waters. The results from this modeling study suggest that the net effect of increased stratification and temperature conditions is a decrease in carbon export in the Cold Tongue region and a shift in the phytoplankton community towards smaller algal forms (e.g., Prochlorococcus spp. and Synechecoccus). Increased stratification can result in decreased iron concentration and reduced vertical velocities, both of which contribute to decreased carbon export. Also, stratified conditions enhance the remineralization rate of nutrients (e.g., iron), which enhances carbon production. Thus, inclusion of iron dynamics in climate models may be needed to fully represent the effect of climate variability on equatorial Pacific ecosystems.
\end{abstract}

1. Center for Coastal Physical Oceanography, Old Dominion University, Norfolk, Virginia, 23529, U.S.A.

2. Present address: Institute of Marine Sciences, Middle East Technical University, Erdemli, Turkey.

3. Corresponding author. email: baris@ims.metu.edu.tr 


\section{Introduction}

The equatorial Pacific Ocean has a major role in the global carbon budget. It is the largest region of oceanic upwelling and the high carbon content of upwelled waters makes this region the largest natural source of $\mathrm{CO}_{2}$ to the atmosphere (Takahashi et al., 1997; Chavez et al., 1999). At the same time, high primary production associated with upwelling results in an increase in the magnitude of the biological pump which transfers carbon taken up by phytoplankton out of the surface ocean via sinking of particles. Although, upwelling provides waters rich in macronutrients to the surface ocean, compared to available macronutrient concentration (e.g., typical nitrate concentrations of $\sim 5 \mu \mathrm{M}$, Chavez et al., 1996), the equatorial Pacific is characterized by modest chlorophyll concentrations of 0.2 to $0.3 \mu \mathrm{g}^{-1}$ (Chavez et al., 1999). This high-nutrient, low-chlorophyll (HNLC) environment has been attributed to low iron concentrations (Martin et al., 1994; Coale et al., 1996a,b; Barber et al., 1996) and high zooplankton grazing rates (Walsh, 1976; Cullen et al., 1992; Landry et al., 1997).

The property that is unique to the equatorial Pacific Ocean is that it is the principal site of the El Niño-Southern Oscillation (ENSO), which is the primary cause of interannual climate variability in the tropical Pacific ocean (Philander, 1990). The equatorial Pacific marine ecosystem is also affected by Kelvin waves (Kessler et al., 1995; Chavez et al., 1998), advection of oligotrophic waters (Chavez et al., 1998; Le Borgne et al., 2002), tropical instability waves (TIWs, Qiao and Weisberg, 1995; Yu et al., 1995), equatorially trapped internal gravity waves (IGWs, Wunsch and Gill, 1976; Friedrichs and Hofmann, 2001), and variations in the strength and depth of the Equatorial Undercurrent (EUC, Barber et al., 1996). The available studies consider the response of the equatorial Pacific phytoplankton communities to these physical forcings, which occur at a range of space and time scales (Bidigare and Ondrusek, 1996; Chavez et al., 1998; Friedrichs and Hofmann, 2001) and are variable so that individual events can significantly alter local primary production, species composition, and carbon export. These studies provide the basis for the first research objective of this study which is directed at identifying and quantifying the response of equatorial Pacific phytoplankton communities to different physical forcings and the implication of these responses for carbon production and export.

Pigment and size fractionated studies of equatorial Pacific phytoplankton communities indicate that Prochlorococcus, Synechococcus, autotrophic eukaryotes, and large ( $\sim 20 \mu \mathrm{m}$ cell size) diatoms represent the dominant autotrophic biomass (Lindley et al., 1995; Bidigare and Ondrusek, 1996; Chavez et al., 1996; Coale et al., 1996b; Landry et al., 1996; Latasa et al., 1997; Higgins and Mackey, 2000; Landry et al., 2000a). The carbon biomass, chlorophyll $a$ and primary production of each of these phytoplankton algal groups can be regulated by biological interactions as well as by physical forcing. The second research objective is directed at understanding the role of biological processes and interactions in regulating carbon biomass, chlorophyll $a$ concentration, and primary production of the dominant algal groups composing equatorial Pacific phytoplankton communities. 
The abundance and distribution of dissolved iron (Morel et al., 1991; Martin et al., 1994; Coale et al., 1996a,b; Barber et al., 1996), the ambient and cellular iron to nitrogen and iron to carbon ratios (Sunda and Huntsman, 1995), the remineralization and scavenging of iron (Hutchins et al., 1993), and the magnitude, distribution and solubility of the aeolian iron flux Fung et al. (2000) are recognized as important contributers to the regulation of phytoplankton community by iron. These observations underline the third research objective which is focused on understanding the role of iron limitation in regulating the production and composition of the equatorial Pacific phytoplankton community.

The three primary research objectives are addressed using a multi-component marine ecosystem model which is described in detail in an accompanying paper (Salihoglu and Hofmann, 2007, this issue) and only explained briefly in the next section. Section 3 presents results of sensitivity studies that are designed to highlight important physical and biological processes that affect carbon production and export. Section 4 discusses the results and places them within the current understanding of the factors controlling lower trophic level production in the eastern equatorial Pacific. The final section summarizes the results from this study.

\section{Model Structure}

Details of the lower trophic level model are given in an accompanying paper (Salihoglu and Hofmann, 2007, this isssue) and are described only briefly here. In this study a onedimensional, algal group-based phytoplankton model (e.g., Bissett et al., 1999a) is used to simulate phytoplankton dynamics in the upper $120 \mathrm{~m}$ of equatorial Pacific Ocean. The phytoplankton model is part of a lower trophic level ecosystem model that is coupled to a larger model structure that provides the forcing fields.

The simulated surface light field, which provides input to the underwater light field is obtained from a clear sky spectral irradiance model (Gregg and Carder, 1990) that is corrected for cloud cover effects using the shortwave radiation measurements from the Tropical Ocean-Global Atmosphere (TOGA) program and the Tropical Atmosphere-Ocean (TAO) Array observations. The spectral attenuation of light energy with increased water depth is estimated as a function of the spectral absorption and backscattering of the water and particulate materials and used to force the full-spectral, algal group-based phytoplankton model. The pigment concentrations estimated for each algal group in the phytoplankton model are used to estimate particulate material concentration as a feedback into the biooptical model.

The effects of the physical environment are included in the ecosystem model using the advective velocity and temperature time series from the TAO mooring. Similarly the time varying mixed layer depth obtained from the TAO mooring measurements and the theoretically derived vertical diffusion coefficients are input into the ecosystem model.

Atmospheric (aeolian) deposition of iron provides another input for the lower trophic level ecosystem model because iron is believed to limit phytoplankton growth in equatorial 
Pacific waters. Aeolian iron deposition is estimated using the monthly atmospheric dust flux, which is obtained from Ginoux et al. (2001).

The phytoplankton algal groups $(A G)$ included as state variables in the ecosystem model represent the dominant autotrophic biomass in the equatorial Pacific as determined from pigment and size fractionated studies (Chavez, 1989; Iriarte and Fryxell, 1995; Lindley et al., 1995; Bidigare and Ondrusek, 1996; Chavez et al., 1996; Coale et al., 1996b; Landry et al., 1996; Latasa et al., 1997; Higgins and Mackey, 2000; Landry et al., 2000a) and are sufficient to represent over $90 \%$ of the equatorial Pacific phytoplankton biomass. The accessory pigments included in the model are categorized as chlorophyll $a$, chlorophyll $b$, chlorophyll $c$, photosynthetic carotenoids, photoprotective carotenoids, and phycoerythrin. The five algal groups represent low-light adapted Prochlorococcus, high-light adapted Prochlorococcus, Synechecoccus, autotrophic eukaryotes and microplankton (large diatoms).

The current consensus is that nitrogen and iron both limit primary production in the eastern and central equatorial Pacific Ocean (Martin et al., 1990, 1991; Price et al., 1994; Behrenfeld et al., 1996; Coale et al., 1996a; Landry et al., 1997, 2000a) and that silicate limits diatom growth (Dugdale and Wilkerson, 1998). This understanding is included in the formulations used for growth of the five algal groups, which incorporates uptake of ammonium, nitrate, iron, and silicate. All of the algal groups use ammonium and iron; whereas, nitrate is only used by algal group 3, algal group 4, and algal group 5. Silicate is only used by algal group 5 .

Each algal group has cellular carbon, nitrogen (ammonium + nitrate), and iron compartments and algal group 5 has a cellular silicate compartment. The phytoplankton cellular nitrogen, iron, and silicate are needed to calculate uptake of nitrogen, iron and silicate by phytoplankton and to estimate nitrogen, iron and silicate limited growth rates. The chlorophyll $a$ equations are linked to cellular carbon, nitrogen, and iron state equations by variable cellular carbon to chlorophyll $a$, nitrogen to chlorophyll $a$, and iron to chlorophyll $a$ ratios. The estimation of carbon to chlorophyll $a$ ratios of each algal group are estimated using the procedure given in Bissett et al. (1999b).

Two groups of zooplankton are included in the ecosystem model which represent microzooplanton and mesozooplankton. Microzooplankton graze on Prochlorococcus spp., Synechecoccus, and autotrophic eukaryotes. The mesozooplankton graze on large diatoms and microzooplankton (Dam et al., 1995; Landry et al., 1995; Zhang et al., 1995; Verity et al., 1996).

The detrital component of the ecosystem model is divided into small and large detritus groups. Detrital components are split into two groups because each group has unique sinking and remineralization rates (Nelson et al., 1995; Laws et al., 2000). The small detrital pool receives inputs from algal groups 1-4 that results from losses due to non-grazing mortality. Additional inputs to this detrital pool are from microzooplankton excretion and fecal pellet production (unassimilated ingestion). Losses by algal group 5 from non-grazing mortality and mesozooplankton excretion and fecal pellet production provide the inputs to the large 
detrital pool. Remineralization of small and large detritus provide sources of ammonium and iron (Laws et al., 2000). Dissolution of silicate in the large detritus compartment provides a source for this nutrient (Nelson et al., 1995).

Forcing by the physical environment acts on all model state variables. The detritus compartments are also allowed to sink at a fixed rate.

\section{Results}

\section{a. Model sensitivity to model structure}

$i$. Algal group effect. To investigate the effect of each algal group on the structure and function of the lower trophic level ecosystem, simulations were done in which particular algal groups were eliminated from the model structure. The simulated annual integrated biomass, primary production, and annual carbon flux were calculated for each of these simulations and compared to the equivalent values obtained from the reference simulation.

The absence of algal group 4 has the most effect on the annual integrated biomass relative to the biomass obtained from the reference simulation (Fig. 1). Without algal group 4, the annual integrated biomass is $20 \%$ less compared to the reference simulation results. The absence of algal groups 1,2,3, and 5 results in a reduction in the annual integrated biomass of $10 \%$ or less. The main characteristics of algal group 4 gives it an advantage over other groups and therefore results in a higher decrease in total biomass when it is removed from the model. For example, this group can adapt better to low nutrient conditions compared to algal group 5, and it can avoid grazing pressure better compared to smaller forms (i.e. algal groups 1-3).

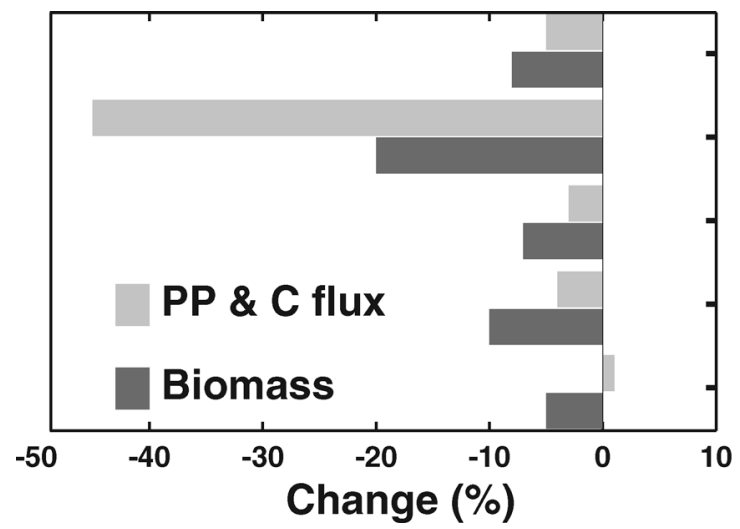

AG5 removed

AG4 removed

AG3 removed

AG2 removed

$A G 1$ removed

Figure 1. Change (\%) in annual integrated biomass, primary production (PP), and carbon fluxes (C flux) at $120 \mathrm{~m}$ produced when each algal group is removed from the model structure. The bars show the difference between the reference simulation and simulations with the modified model structure. The primary production and carbon flux changes are of similar magnitudes and are shown by a single bar. 
Removal of algal group 4 results in a $45 \%$ decrease in annual integrated primary production relative to the reference simulation. Considering that the reference simulation results show that this group is responsible for $69 \%$ of the annual primary production (Salihoglu and Hofmann, 2007, Table 3), this result indicates that other groups replace $35 \%$ of carbon originally produced by this group. The absence of algal groups 2, 3, and 5 results in reductions in integrated primary production of $5 \%$ or less. Removal of algal group 1 actually results in an increase in integrated primary production of about $1 \%$. The effect of the absence of each algal group on carbon fluxes is similar in magnitude to the effect on primary production (Fig. 1).

ii. Nutrient uptake. A unique characteristic of the lower trophic level ecosystem model is that Prochlorococcus spp., algal groups 1 and 2, use only ammonium (Moore et al., 2002). Modifications of the model structure to allow these algal groups to use nitrate results in increased Prochlorococcus spp. primary production of 17\%, which corresponds to an increase of $7 \%$ in the primary production of the whole algal community. This implies that this level of physiological detail needs to be included in biogeochemical and carbon cycling models. This modification in Prochlorococcus spp. nutrient uptake dynamics does not cause a significant change in the primary production of the other algal groups.

\section{b. Model sensitivity to model dynamics}

$i$. Iron concentration. The response of the lower trophic level ecosystem to changes in iron concentration was examined by doubling or halving the iron concentration at the base of the euphotic zone. Doubling the iron concentration at the base of the euphotic zone does not produce an iron replete upper ocean because of high iron uptake by phytoplankton. Iron concentration in surface waters still remains below the detection limit of $0.03 \mathrm{nmol}^{-1}$. The increased iron at the base of the euphotic zone only affects the iron concentration during upwelling of waters from $120 \mathrm{~m}$. It has little influence during downwelling periods.

Annual integrated primary production increases by $33 \%$ when the iron concentration at the base of the euphotic zone is doubled. Algal group 4 shows the largest response to increased iron, with a primary production increase of 46\% (Fig. 2). Algal groups 2 and 3 show increased primary production of $7 \%$ and 5\%, respectively (Fig. 2). Increased iron results in reduction of the integrated primary production of algal groups 1 and 5 of $12 \%$ and $10 \%$, respectively (Fig. 2). This decrease in algal group 5 is not realistic and is further discussed in Section 4ci.

The increased iron concentration at $120 \mathrm{~m}$ results in only a $10 \%$ increase in the annual integrated biomass of the phytoplankton community. The increases in annual integrated biomass of algal groups 3 and 4 are less than the increases in their primary production values (Fig. 2). Increased iron concentration does not affect algal group 2 biomass, but produces a decrease in the biomass of algal groups 1 and 5 that is larger than the decrease in their primary production. 


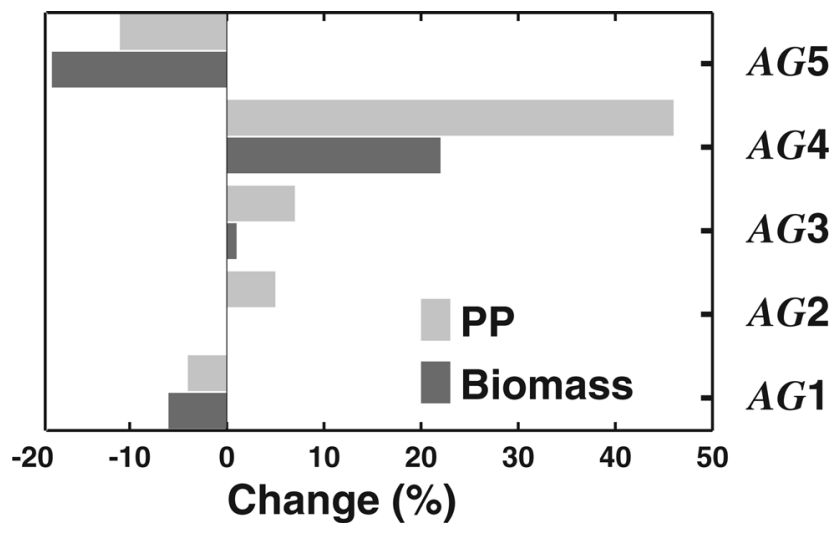

Figure 2. Change (\%) in annual biomass and primary production (PP) of each algal group ( $A G)$ in response to doubling the iron concentrations at $120 \mathrm{~m}$. The bars show the percent difference between the reference simulation and the modified model run.

The magnitude of response of the lower trophic levels to a 50\% reduction in iron concentration at the base of the euphotic zone is less than their response to a 2-fold increase in iron (Fig. 3). The reduction in iron concentration gives a decrease in annual primary production of $21 \%$, and a decrease in annual integrated biomass of $6 \%$. Algal group 4 is the most affected by decreased iron, with a $27 \%$ decrease in primary production.

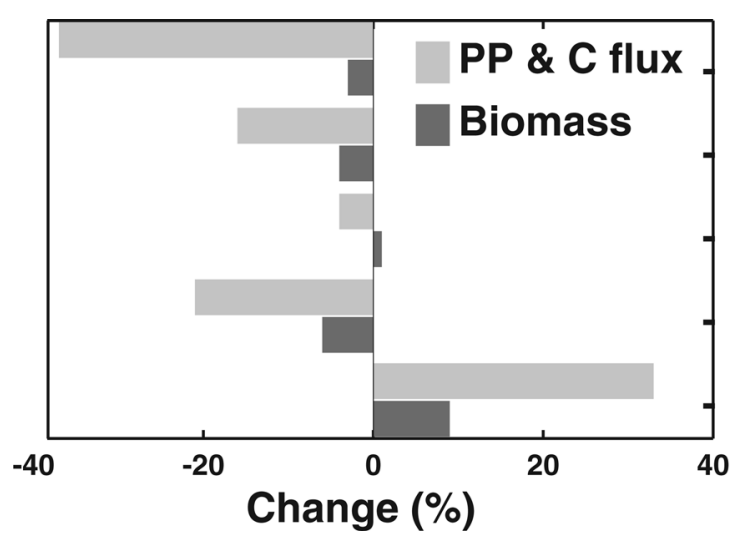

No Fe remin

No atm $\mathrm{Fe}$ input

No Fe scav

Fe $\times 0.5$

$\mathrm{Fe} \times 2$

Figure 3. Change (\%) in annual integrated biomass, primary production (PP), and carbon flux (C flux) at $120 \mathrm{~m}$ in response to modifications in the manner in which iron is supplied. The bars show the percent difference obtained between the reference simulation and simulations in which iron $(\mathrm{Fe})$ concentrations at $120 \mathrm{~m}$ are doubled $(F e \times 2)$, reduced by $50 \%(F e \times 0.5)$, no iron scavenging (scav), no atmospheric (atm) iron deposition and no remineralization (remin). For the case where remineralization is modified (No Fe remin) the grey bar only represents primary production. 
Unlike the macronutrients, iron can be provided by atmospheric deposition and removed by particle scavenging. Elimination of the atmospheric iron flux results in a $16 \%$ decrease in annual integrated primary production and carbon fluxes (Fig. 3). Algal group 4 responds most strongly to the loss of this iron source, with reductions in primary production rate and biomass of $11 \%$ and $19 \%$, respectively. Iron scavenging by particles, in contrast, does not have an appreciable effect on primary production, producing only a $4 \%$ decrease when not active (Fig. 3). This result agrees well with observations that show that at low iron concentrations ( $<\sim 0.6 \mathrm{nM})$ most ( $>99 \%)$ of the dissolved iron is bound to organic ligands and is not strongly particle reactive (Van den Berg, 1995; Rue and Bruland, 1995, 1997). Overall, comparison of the effects of the different modifications to the iron sources (Fig. 3), shows that the changes in primary production and carbon fluxes are always greater than biomass changes.

ii. Silicate concentration. The reference simulation results indicate that algal group 5 is not silicate limited because silicate values were rarely below $3 \mu \mathrm{mol}^{-1}$. To test the response of the algal groups to reduced silicate concentrations, silicate at the bottom of the euphotic zone was reduced by $50 \%$. This reduction resulted in a $\sim 50 \%$ decrease in integrated silicate concentration (Salihoglu, 2005). However, reducing silicate at the bottom of the euphotic zone mainly reduces the high silicate concentrations that occur during upwelling events and does not affect the low silicate values during downwelling periods. Therefore, only a slight decrease of $1 \%$ in primary production of algal group 5 results from reduced silicate concentrations.

\section{c. Parameter sensitivity}

Many of the parameters used in marine ecosystem models are not well constrained by measurements (Doney, 1999). Information on zooplankton grazing rates is very limited (Armstrong, 1994). Little information is available on cellular nutrient concentration ratios of different algal groups (Sunda and Huntsman, 1995; Geider et al., 1998; Takeda, 1998). Also, there are still many unanswered questions concerning the recycling (remineralization) of iron in oceanic surface waters (Bruland et al., 1994; Wells et al., 1995; Johnson et al., 1997; Fung et al., 2000; Jickells and Spokes, 2002).

In this study, the sensitivity of the model solutions to variations in zooplankton grazing rates, cellular nutrient concentration ratios, and iron remineralization was tested. In previous studies, Friedrichs and Hofmann (2001) used $\pm 25 \%$ difference of original parameter values and Fennel et al. (2003) used a difference of $\pm 50 \%$. In this study a difference of $\pm 25 \%$ is preferred, because this difference is within the variance of environmental conditions for the grazing rates (Landry et al., 1995; Verity et al., 1996), cellular nutrient concentrations (Sunda and Huntsman, 1995) and iron remineralization (Bruland et al., 1994; Johnson et al., 1997). The effect of variations in these parameters was assessed using yearly primary production, vertical carbon fluxes at $120 \mathrm{~m}$, carbon biomass of the 5 algal groups, and the concentrations of nutrients as diagnostics. 
i. Grazing. Simulation results show that the magnitude of the phytoplankton biomass depends strongly on the grazing parameters. Variation of the microzooplankton grazing rates of $\pm 25 \%$ produces $\sim \pm 19 \%$ changes in primary production and biomass. This magnitude of change is indicative of an ecosystem under top-down control (Klein and Steele, 1985). A similar change in primary production and biomass is observed when the grazing rates of mesozooplankton are varied, but the nature of the change is complex. For example, reduced grazing pressure on microzooplankton by mesozooplankton results in increased grazing pressure on phytoplankton by microzooplankton which reduces the phytoplankton biomass. Variations in the mesozooplankton grazing rate have the strongest influence on algal group 5, because this group is directly grazed by mesozooplankton. A $25 \%$ decrease in the mesozooplankton grazing rate resulted in a $27 \%$ increase in algal group 5 annual primary production and biomass.

ii. Cellular iron to carbon ratios. In the model, growth rates of the algal groups are estimated as a function of cellular nutrient concentrations (Salihoglu and Hofmann, 2007). Specified minimum cellular nutrient to carbon ratios set the limit for zero growth rate. Because iron is the primary nutrient limiting phytoplankton growth at $0 \mathrm{~N}, 140 \mathrm{~W}$, only variations in the cellular iron to carbon ratio ( $K_{Q F e}$, Salihoglu and Hofmann, 2007, Table 3) were tested.

Perturbing minimum cellular iron to carbon ratios by $\pm 25 \%$ results in a $\pm 11 \%$ variation in primary production and export flux and no significant effect in biomass relative to the reference simulation. The effect of changing the iron to carbon ratio is greatest for algal groups 4 and 5 compared to the other algal groups. For example, decreasing the minimum limit of iron to carbon ratios by $25 \%$ results in an increase of $20 \%$ in algal group 4 primary production, and essentially no effect on algal group 1 .

iii. Iron remineralization. Recycled iron via remineralization is responsible for $40 \%$ of the simulated annual primary production and about $3 \%$ of the annual integrated biomass (Fig. 3). The effect of recycled iron on the primary production differs for each algal group. Algal group 4 responds most strongly, with its production reduced by half when iron remineralization is not active. The primary production of algal groups 2 and 3 also decreases (30 and $37 \%$ decrease, respectively). However, the absence of iron remineralization enhances the primary production of algal groups 1 and 5 by 20 and 30\%, respectively. This increase is due to decrease in high grazing pressure on these groups.

\section{d. Model sensitivity to physical forcing}

i. Effects of modified physical forcing fields. To investigate the effects of variations in environmental forcing on the lower trophic levels, the model was forced with time series of vertical velocity $(w)$, diffusivity coefficient $\left(K_{z}\right)$, mixed layer depth, temperature $(T)$, and light that were modified relative to the ones used in the reference simulation. Temperatures at $120 \mathrm{~m}$ determine the concentrations of nutrients, which are carried into surface waters via 


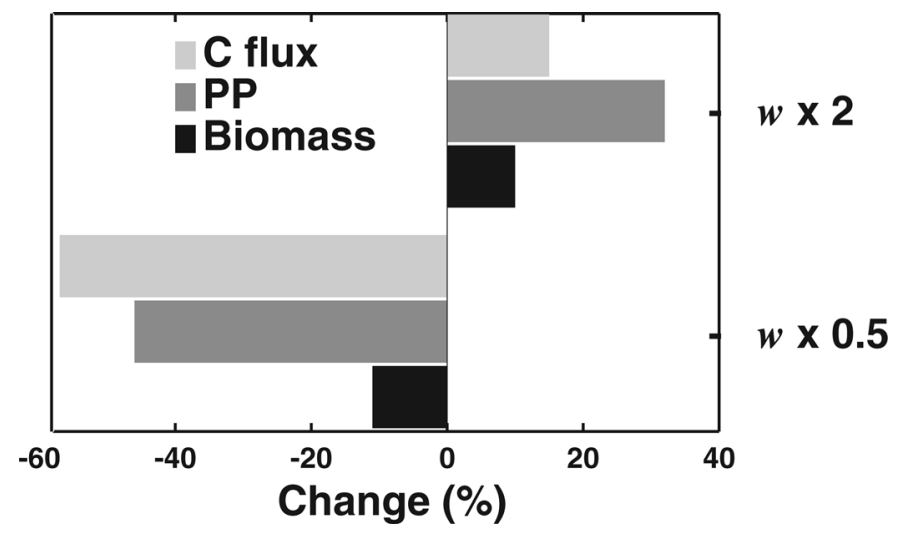

Figure 4. Change (\%) in annual biomass, primary production (PP), and carbon fluxes (C flux) at $120 \mathrm{~m}$ in response to modifications in the vertical velocity time series that is input into the model. The bars show the percent difference between the reference simulation and simulations in which the vertical velocities $(w)$ at $120 \mathrm{~m}$ were doubled $(2 \times w)$ and reduced by $50 \%(0.5 \times w)$.

upwelling, mixing in the mixed layer, and diffusion. The light field is one of the main driving mechanisms for algal growth (Salihoglu and Hofmann, 2007). The effect of the modified environmental time series was assessed by comparing the annual phytoplankton biomass and primary production estimates and carbon fluxes at 120 obtained from the simulations. Modifications on vertical velocities is applied to both negative (downwelling) and positive (upwelling) velocity values. For example when the vertical velocity is decreased by $50 \%$ both downwelling and upwelling values are decreased by half.

Primary production is most sensitive to decreased vertical velocity (Fig. 4), with a 50\% decrease in vertical velocity producing a $46 \%$ decrease in annual primary production. The response of the annual integrated phytoplankton biomass to reduced vertical velocities is less, with only an $11 \%$ reduction. Increasing vertical velocities by $50 \%$ results in a $32 \%$ increase in annual primary production (Fig. 4). Annual biomass increases by $10 \%$, indicating a decoupling in the responses of primary production and biomass. The change in carbon flux resulting from decreased vertical velocity is similar to what is seen for primary production, with a $58 \%$ decrease at $120 \mathrm{~m}$. Increasing vertical velocity produces only a $15 \%$ increase in carbon flux at $120 \mathrm{~m}$, this is further discussed in Section 4a.

Increased vertical velocities shift the phytoplankton community assemblage towards larger algal groups, with the primary production of algal groups 4 and 5 increasing by $43 \%$ and $22 \%$, respectively. Although the primary production of algal group 5 increases considerably, its biomass is essentially unchanged from that in the reference simulation. Primary production associated with the other groups is only slightly modified by increased vertical velocities.

Fixing the mixed layer at the annual mean value of $44 \mathrm{~m}$, produces a shallower mixed layer during El Niño conditions (first four months of the year) and a deeper mixed layer later 
in the year (Salihoglu and Hofmann, 2007, Fig. 3C). The deeper mixed layer post-El Niño results in an annual increase in primary production of $17 \%$. A deeper mixed layer favors all of the groups, except algal group 1. A deeper mixed layer results in these phytoplankton cells being moved into the high-light surface waters, which produces light inhibition of growth.

A constant minimal vertical diffusive flux $\left(K_{z}\right)$ of $0.036 \mathrm{~m}^{2} \mathrm{~d}^{-1}$ decreases the annual primary production and carbon flux by $13 \%$ and $14 \%$, respectively. Decreased vertical diffusive fluxes result in a decrease in total annual algal biomass, although this decrease $(5 \%)$ is much less than the decrease in annual integrated primary production. Algal group 1 is the most affected group, with a $17 \%$ increase in biomass. The biomass of the other algal groups decreases with algal group 4 being the most affected group (11\% decrease in biomass). Decrease in primary production mainly occurs because of reduced diffusive fluxes at the base of the mixed layer which introduces nutrients into the mixed layer.

Temperature determines the nutrient levels at the bottom of the model domain (Salihoglu and Hofmann, 2007, Section 3), and affects the growth rates of algal groups (Salihoglu and Hofmann, 2007, Section 3). Thus, a 5C increase in temperature results in a decrease in nutrient concentrations and an increase in phytoplankton growth rates. Also increased temperatures result in increased nutrient remineralization rates (Salihoglu and Hofmann, 2007, Section 3). Therefore, the effect of temperature change is a nonlinear response that results in different responses from different parts of the ecosystem. In the simulations, decreased nutrient levels at the bottom of the euphotic dominate over increased growth rates and remineralization rates, and a $5 \mathrm{C}$ increase in temperature results in a small (5\%) decrease in simulated total annual primary production.

The effect of cloud cover on photosynthetic potential of the algal groups was investigated with simulations that did not include cloud reduction of the surface irradiance (i.e. clear sky). These simulations show that the effect of cloud cover on the total annual primary production is small (4\% increase) for 1992 because the cloud cover in the region was not extensive for this time. Comparison of the simulations with and without clouds, however, shows that clouds can inhibit or dampen phytoplankton blooms. For example, with clear sky conditions a phytoplankton bloom occurs between Year Day (YD) 60 and YD90, which is not present in the simulations that include cloud cover.

The effect of cloud cover on each algal group also differs, with small groups (algal groups 1 to 3 ) being the most affected groups. The removal of cloud cover results in an increase in primary production of algal groups 1 to 3 by $\sim 8 \%$; whereas, the increase in primary production of algal group 4 is less $(1 \%)$ and primary production by algal group 5 is decreased by $3 \%$.

ii. Relative effects of physical forcings at different frequencies. The environmental time series used to force the reference simulation exhibit variability over a wide range of time scales. To investigate the effect of variability at the different time scales, the model was forced with a constant mean vertical velocity for $1992\left(1.6 \mathrm{~m} \mathrm{~d}^{-1}\right)$, time series that were 40-day low-pass filtered (Figs. 5A-D), which retain low frequency motions such as Kelvin 

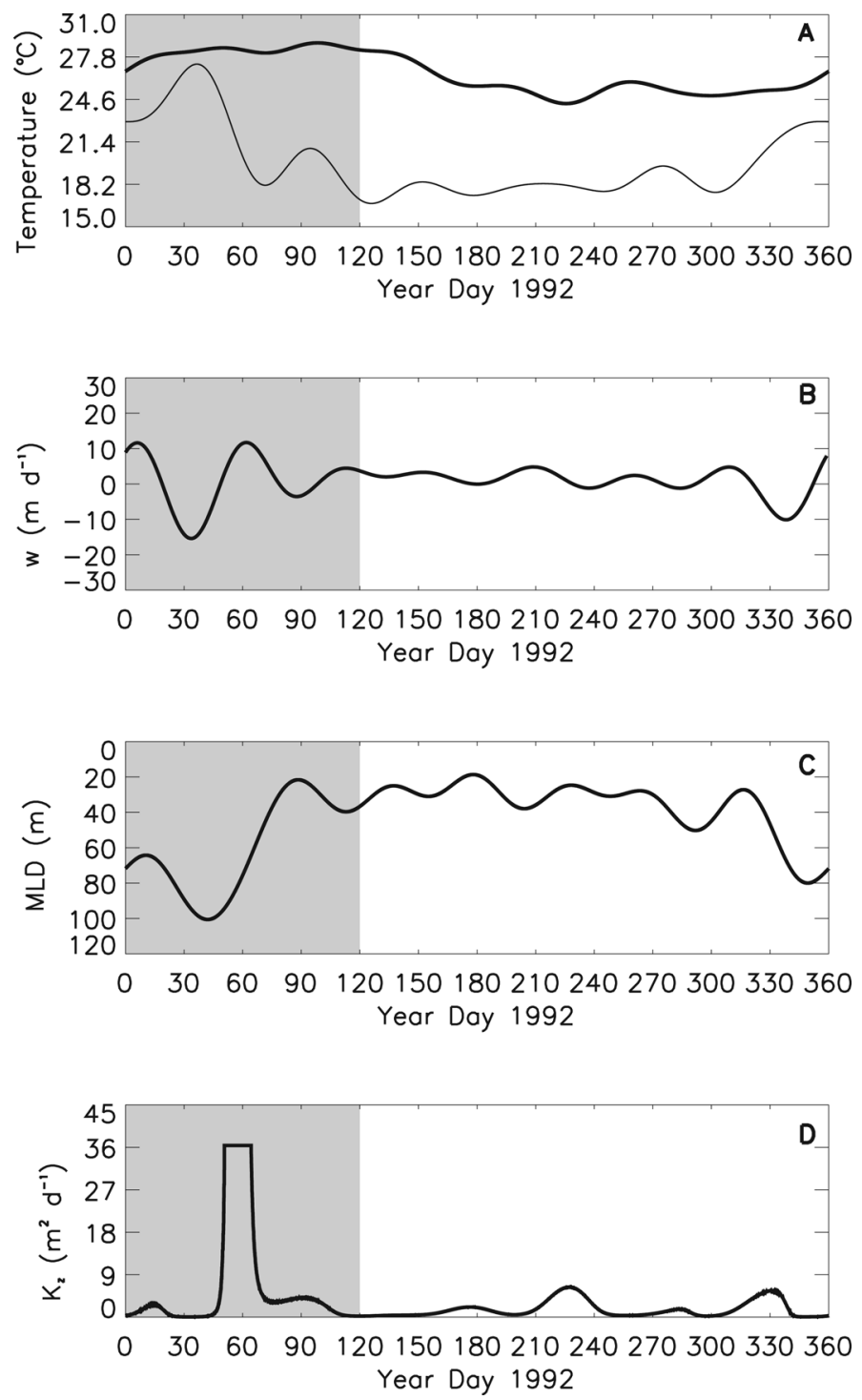

Figure 5. Time series of 40-day low-pass filtered (A) surface temperature (thick solid line) and temperature at $120 \mathrm{~m}$ (thin solid line), (B) vertical velocity $(w)$ at $40 \mathrm{~m},(\mathrm{C})$ mixed layer depth (MLD), and (D) vertical diffusivity coefficient $\left(K_{z}\right)$ at $25 \mathrm{~m}$ estimated from observations obtained from the TAO mooring at 0N, 140W as discussed in Salihoglu and Hofmann (2007). Fast Fourier Transform (FFT) is used to determine the frequency spectra and to low-pass filter the time series. By using the FFT the high frequency motions with periods lower than 40 days are removed. Shaded regions denote the El Niño season. 
waves, and time series that were 20-day high-pass filtered (Figs. 6A-D), which retain most of the high frequency motions such as TIWs and IGWs.

For a constant positive vertical velocity (upwelling) recycled iron is not removed from the surface waters and as a result accumulates below the mixed layer. This artificial accumulation of iron results in a $25 \%$ increase in phytoplankton primary production. A constant vertical velocity removes the high frequency variability in the phytoplankton biomass and increases the difference in biomass between the first and latter parts of 1992.

Modification of the environmental time series by filtering out high (Figs. 5A-D) or low (Figs. 6A-D) frequency motions reduces the advective loss of recycled iron from the lower boundary of the model, which artificially accumulates iron below the mixed layer. As a result, the high and low-pass filtered vertical velocity fields yield increased primary production of $47 \%$ and $15 \%$, respectively.

Analysis of the frequencies of the motions in the vertical velocity fields shows that in 1992 motions with periods of 42-75 days dominated, which is reflected in the phytoplankton distributions obtained from the reference simulation (Salihoglu and Hofmann, 2007, Fig. 17). The 40-day low-pass filtered time series (Figs. 5A-D) produces periodicity in the simulated algal groups with frequencies of 42-75 days (Fig. 7A). Moreover, the low frequency motions are responsible for the sustained ( $\sim 40$ days) decreases in algal biomass, such as those that occur during YD30-YD60, YD80-YD120, and YD160-YD220 (Fig. 7A). The amplitudes of the fluctuations in biomass are larger than those seen in the reference simulation. For example, the biomass of algal group 4 in the mixed layer increases by a factor of 5 between YD105 and YD130 (Fig. 7A); whereas, the reference simulation shows a tripling in biomass for this algal group during the same time period. A similar trend is also observed for algal group 5.

The time series analysis of the vertical velocities also showed significant variability at frequencies of 8-26-days, which includes TIWs (20-day period, Qiao and Weisberg, 1995; Yu et al., 1995) and IGWs (6-8-day period, Wunsch and Gill, 1976; Friedrichs and Hofmann, 2001). Input of the high-pass filtered environmental time series (Figs. 6A-D) shows that these high frequency motions produce fluctuations in phytoplankton biomass that have smaller amplitudes than those produced by the low frequency time series (Fig. 7B). Also, the amplitude of the variability is smaller compared to the biomass distributions obtained from the reference simulation. Total phytoplankton biomass is higher than observations, and the difference in biomass (relative to the reference simulation) between the El Niño part of the year and the rest of the year decreases.

The highest simulated algal biomass occurs on YD285 (Fig. 7B) which happens to coincide with the time of observations made during the U.S. Joint Global Ocean Flux Study (JGOFS) 20-day time series cruise that took place in October (TS2). The algal biomass for the rest of the simulations is lower, which is in contrast to the reference simulation results which show three other periods with algal biomass that is higher than observed during the TS 2 cruise. The high frequency environmental time series result in increases in the biomass of algal groups 4 and 5 during the El Niño period relative to the other groups. 

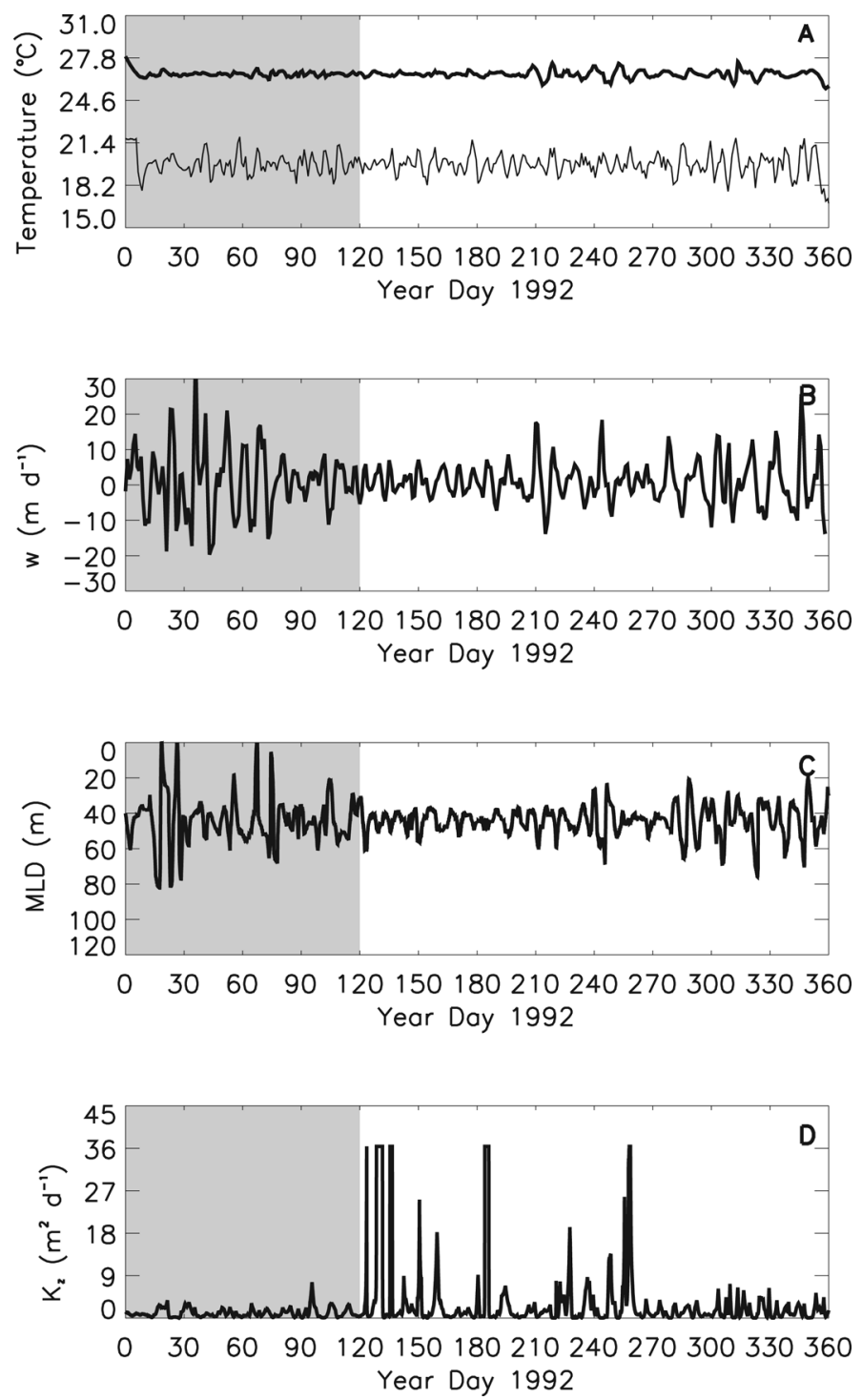

Figure 6. Time series of 20-day high-pass filtered (A) surface temperature (thick solid line) and temperature at $120 \mathrm{~m}$ (thin solid line), (B) vertical velocity $(w)$ at $40 \mathrm{~m},(\mathrm{C})$ mixed layer depth (MLD), and (D) vertical diffusivity coefficient $\left(K_{z}\right)$ at $25 \mathrm{~m}$ estimated from observations obtained from the TAO mooring at 0N, 140W as discussed in Salihoglu and Hofmann (2007). Fast Fourier Transform is used to determine the frequency spectra and to high-pass filter the time series. By using the FFT the low frequency motions with periods higher than 20 days are removed. Shaded regions denote the El Niño season. 

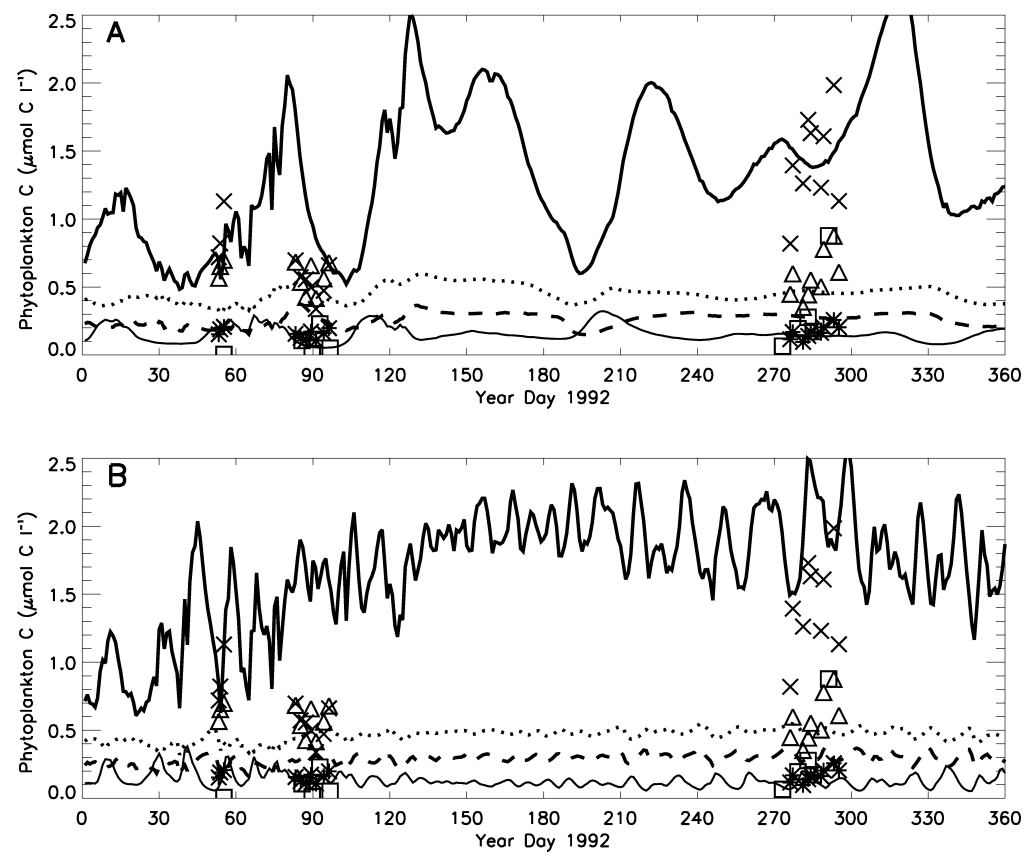

Figure 7. Simulated time distribution of the combined low light-adapted and high light-adapted Prochlorococcus (dotted line), Synechococcus (dashed line), autotrophic eukaryotes (thick solid line), and large diatoms (thin solid line) in the mixed layer ( $\mu \mathrm{mol} \mathrm{C}^{-1}$ ) using the (A) 40-day lowpass filtered environmental time series shown in Figs. 5A-D and (B) 20-day high-pass filtered environmental time series shown in Figures 6A-D. The distrubition of autotrophic eukaryotes (red line) obtained from the reference simulation is given for comparison. The corresponding measurements for each algal group from the four U.S. JGOFS EqPac cruises are shown by $\triangle, *, \times$, and $\square$, respectively. Measurements from the cruises do not distinguish between the two ecotypes of Prochlorococcus spp. Therefore, the simulated biomass values of algal groups 1 and 2 are summed up for comparison with the cruise measurements.

The accumulation of iron below the mixed layer which occurs in response to the filtered environmental time series was eliminated by setting the iron remineralization rate to a very low value $\left(0.01 \mathrm{~d}^{-1}\right)$. For comparison, an equivalent simulation was done with the reference model. Without the effect of iron accumulation, the annual phytoplankton primary production and annual carbon flux decrease by $\sim 5 \%$ in response to low frequency events. High frequency motions increase the annual primary production and the annual carbon flux increases by $\sim 30 \%$. This is further discussed in Section $4 \mathrm{~b}$.

\section{Discussions}

\section{a. Model interactions and feedbacks}

Inclusion of multiple algal groups resolves some basic problems associated with simulating phytoplankton growth and production (Salihoglu and Hofmann, 2007). This model 
structure also makes it possible to analyze the effect of each group on carbon biomass, production, and flux. The results of the simulations (Section 3ai) show that all algal groups have a considerable effect on phytoplankton carbon biomass, but that not all have a strong effect on primary production and carbon flux (Fig. 1). This indicates that carbon cycle models need to include the few key algal groups that have the primary influence on primary production and export variability. It is possible to combine algal groups 1-3 (low-light adapted Prochlorococcus, high-light adapted Prochlorococcus and Synechococcus) under one group (e.g. cyanobacteria group) to form a three algal group model for use in carbon cycle models in the equatorial Pacific region. The first three groups comprise a separate group because of their distinctive nutrient utilization characteristics, as explained in (Salihoglu and Hofmann, 2007, Section 3), and because the carbon budget estimations (Salihoglu and Hofmann, 2007, Section 4) show that these three groups are responsible for a substantial percentage (27\%) of the carbon transfer between the primary producers and the higher trophic levels. A group (i.e. autotrophic eukaryotes) that falls between large diatoms and this cyanobacteria group is also needed as explained in Salihoglu and Hofmann (2007). Both the sensitivity studies (Fig. 1) and the carbon budget estimations (Salihoglu and Hofmann, 2007, Section 4) show that algal group 5 is responsible for a small fraction $(\sim 8 \%)$ of carbon export to higher trophic levels, because of reduced growth rates due to iron limitation. However, this group should be retained in carbon cycle models because iron enrichment experiments done in equatorial Pacific waters (Coale et al., 1996b) showed that large diatoms can be a major contributor to carbon production under iron replete conditions.

The competition for light and nutrients and differential grazing by micro- and mesozooplankton on each algal group regulate the interactions between algal groups. The sensitivity analyses (Section 3ai) show that removal of algal group 4 decreases the simulated annual primary production by $45 \%$ (Fig. 1). Algal group 4 contributes $69 \%$ of the annual primary production. The other groups replace algal group 4 to a certain extent, but their physiological characteristics do not allow complete replacement. Similar results are obtained when the other algal groups were eliminated. Algal group 1 is the only group whose absence results in an increase in primary production (1\%). The nutrients that algal group 1 normally consumes below the mixed layer are taken up by other phytoplankton in the mixed layer (i.e. algal group 4), resulting in a slightly higher production (Fig. 1). These show that the physiological differences included in the algal group model structure gives each algal group the capability and the flexibility to respond differentially to different physical and biological environmental factors.

The simulated phytoplankton biomass is strongly controlled by zooplankton (Section 3c). Increases in primary production stimulate zooplankton grazing which produces increases in zooplankton biomass, resulting in more effective grazing. As primary production decreases, the zooplankton biomass decreases, releasing the grazing pressure on phytoplankton. These interactions between primary production and zooplankton grazing lead to a buffering effect on phytoplankton biomass variability and the variability in primary production is not directly reflected on phytoplankton biomass. 


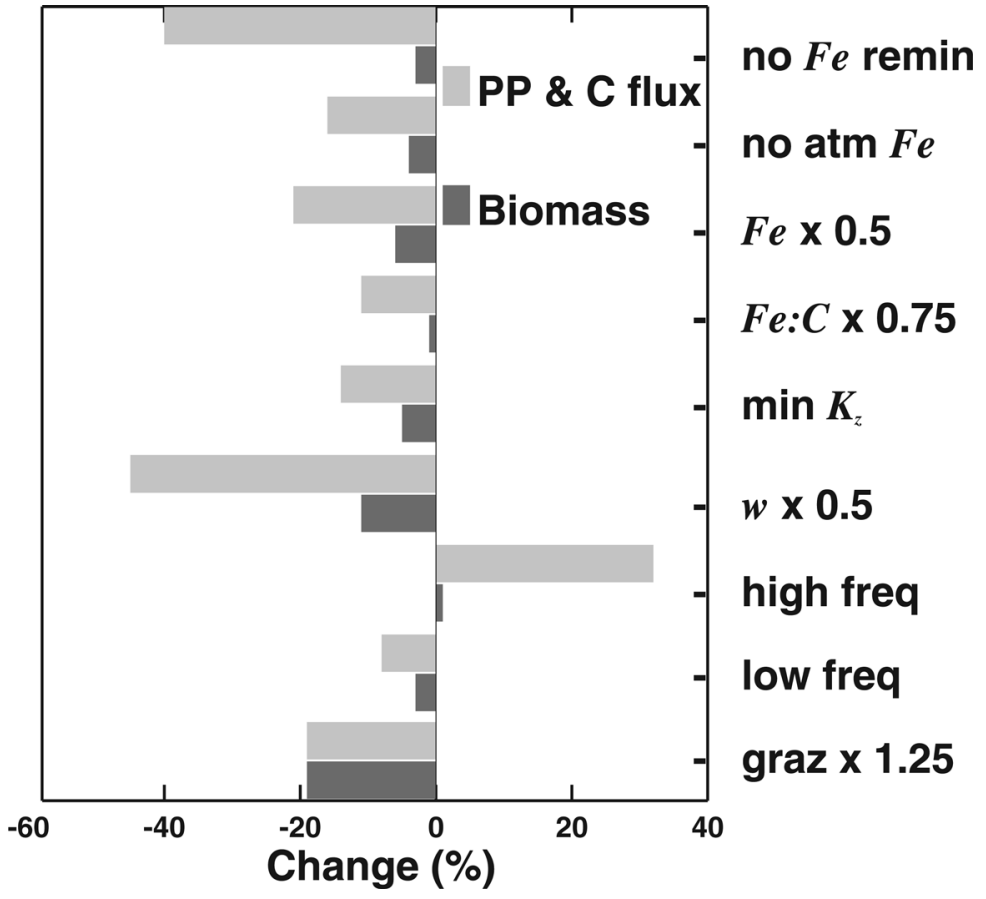

Figure 8. Change (\%) in annual integrated biomass, primary production (PP), and carbon flux (C flux) at 120 meters in response to modifications in model structure. The bars show the difference obtained between the reference simulation and the simulations in which no iron $(F e)$ remineralization (remin), no atmospheric (atm) iron deposition, iron concentrations at 120 reduced by $50 \%$ $(\mathrm{Fe} \times 0.5)$, the maximum cellular iron to carbon $(\mathrm{Fe}: \mathrm{C})$ ratios decreased by $25 \%$, vertical diffusion coefficient $\left(K_{z}\right)$ set to a minimum (min) value, vertical velocity $(w)$ decreased by $50 \%$, model run with filtered 40-day low-pass filtered high frequency (freq) forcings and 20-day low-pass filtered high frequency forcings and after grazing (graz) rate of microzooplankton increased by $25 \%$. The primary production and carbon flux changes are of similar magnitude and are shown by a single bar. For the cases where remineralization (No Fe remin) and grazing (graz x 1.25) are modified the grey bars only represent primary production.

The results from this study support the suggestion that iron regulation and grazing jointly constrain the standing stocks of algal production (Landry et al., 1997). However, principal control on the simulated algal biomass is from grazing rather than iron, and changes in primary production and carbon export are mainly driven by variability in iron concentration. In general, primary production and export carbon flux respond more to changes in environmental forcing of biological processes (Fig. 8) than does phytoplankton biomass; the changes in the two are not linear. The exception is modifications in the strength of the grazing rate, which gives an identical change in primary production and biomass. This suggests that changes in grazing can also be important to primary production. 

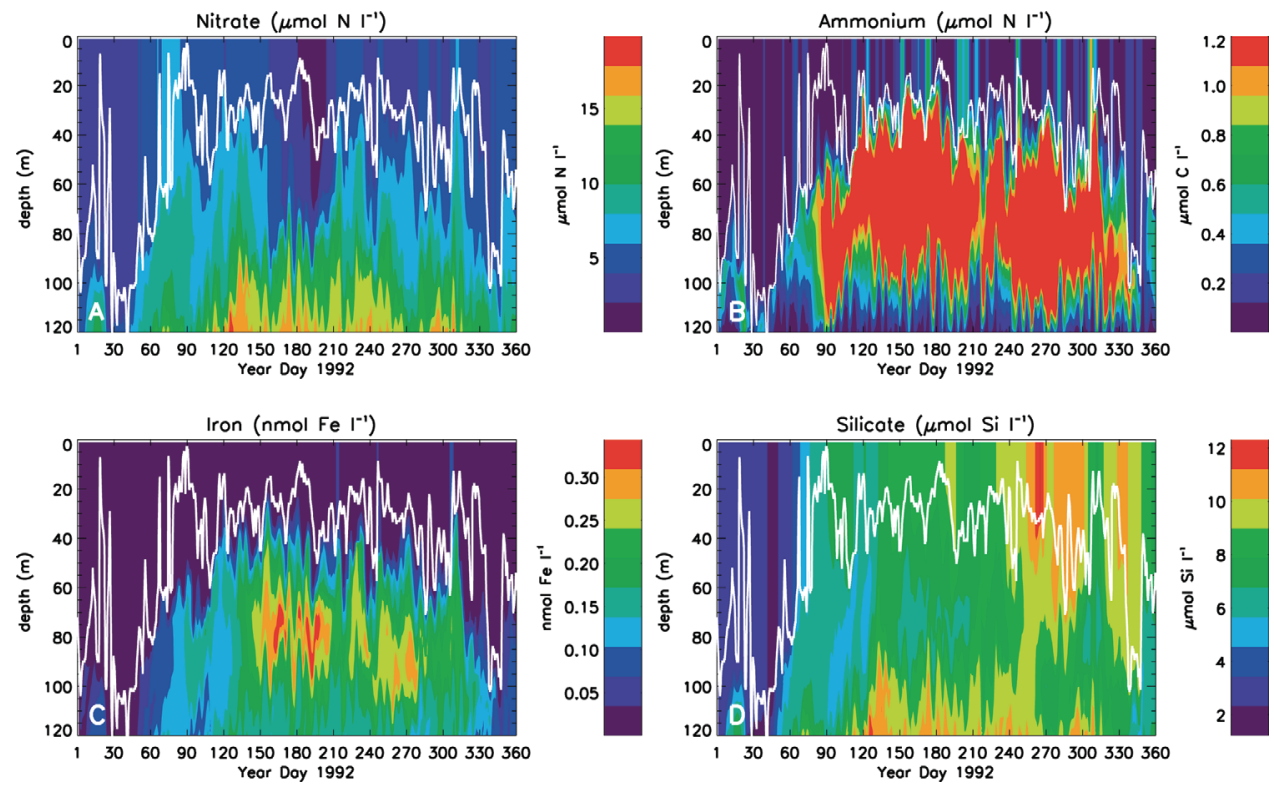

Figure 9. Simulated depth-time distributions of concentrations of (A) nitrate $\left(\mu \mathrm{mol}^{-1}\right)$, (B) ammonium $\left(\mu \mathrm{mol} \mathrm{l}^{-1}\right),(\mathrm{C})$ iron $\left(\mathrm{nmol} \mathrm{l}^{-1}\right)$, and (D) silicate $\left(\mu \mathrm{mol}^{-1}\right)$, obtained by using the reduced detritus sinking rates. Overlaid solid white line represents the mixed layer depth.

Reducing the sinking rates of the small and large detrital pools provide an example of the nonlinear interactions in the lower trophic level model. Reduced sinking rates retain detritus in the euphotic zone longer and thus enhance nutrient production via remineralization. The export carbon flux is then reduced due to less available particulate matter and lower sinking velocities. However, the increased recycling of nitrogen and iron resulted in unrealistic accumulation of recycled nutrients in the euphotic zone (Fig. 9), which results in high carbon production and increased particulate carbon concentrations. The net result is that reduced detritus sinking rates do not change the export carbon fluxes, but rather result in unrealistically high primary production, and ammonium and iron concentrations.

\section{b. Environmental effects}

Because the ecosystem model is forced with observed time series of temperature, vertical velocity, and mixed layer depth it is possible to determine the effect of environmental variability on carbon biomass, primary production, and export production. In particular, the effects of low- and high-frequency physical variability on primary production and export production is of interest for the equatorial Pacific.

Friedrichs and Hofmann (2001) showed variability resulting from IGWs (6-8-d) and TIWs (20-d) dominated the vertical velocity fields at $0 \mathrm{~N}, 140 \mathrm{~W}$. The effect of these high frequency motions appears in the mixed layer depth, $T$ and $K_{z}$ time series input to the ecosystem model (Salihoglu and Hofmann, 2007, Figs. 3A-D). The distribution of simulated phytoplankton 
shows a wide range of temporal variability, and the effect of high frequency variability is clearly seen on simulated phytoplankton biomass (Salihoglu and Hofmann, 2007, Fig. 17) and primary production (Salihoglu and Hofmann, 2007, Fig. 18) and this is reflected in the export carbon fluxes (Salihoglu and Hofmann, 2007, Fig. 14).

Forcing of the ecosystem at $0 \mathrm{~N}, 140 \mathrm{~W}$ with only low-frequency variability (e.g., absence of IGWs, TIWs) reduced annual integrated primary production by $5 \%$ relative to the reference simulation when the iron remineralization is eliminated. The elimination of the iron remineralization from he model helps to evaluate the net influnce of new iron. This result shows that the iron flux to the surface waters is underestimated in the absence of highfrequency events (Section 3d). This supports the results in Friedrichs and Hofmann (2001) that showed if the IGWs are not resolved by the forcing fields the net effect of IGWs and TIWs will need to be parameterized in ecosystem models in order to get realistic primary production estimates in the eastern equatorial Pacific.

The high frequency variability in the simulated phytoplankton biomass decreases when a mean vertical velocity of $1.8 \mathrm{~m} \mathrm{~d}^{-1}$ is input to the ecosystem model. This indicates that the vertical velocity field is producing much of the temporal and spatial variability in phytoplankton biomass. However, the increase in phytoplankton biomass between the first and latter parts of 1992 arises from the initial deeper thermocline which results in reduced upwelling and reduced nutrients injected into the surface. This is consistent with field study results (Barber et al., 1996) that show that the biological processes at $0 \mathrm{~N}, 140 \mathrm{~W}$ are sensitive to changes in thermocline depth.

Variability in the eastern equatorial Pacific also exists on annual/interannual time scales. Recent studies (Chavez et al., 1998; Strutton and Chavez, 2000) demonstrated the influence of Kelvin waves on phytoplankton production during the 1997 El Niño. The biological response to the Kelvin waves during the 1997 El Niño was a depression in primary production. A similar event occurred during 1992 El Niño, the 40-d low-pass filtered time series of temperature, vertical velocity and mixed layer depth show a low frequency event occurring during the first 75 days of 1992 (Salihoglu and Hofmann, 2007, Figs. 3A-C), which reflects passage of a Kelvin wave associated with an ongoing El Niño. The period between YD15-YD50 corresponds to a strong downwelling event, the effect of which is low simulated primary production during this time (Salihoglu and Hofmann, 2007, Fig. 18).

\section{c. Climate change implications}

i. Change in iron input. Sarmiento et al. (2004) suggest that changes in ocean stratification are likely to be one of the main effects of climate warming. In the eastern equatorial Pacific, under stratified conditions, the thermocline deepens as observed during El Niño conditions (Wyrtki, 1975, 1985; Philander, 1990; Hansen, 1990). The observations (Coale et al., 1996a; Chavez et al., 1999; Strutton and Chavez, 2000; Picaut et al., 2002) indicate that the main effect of the change in thermocline depth is a reduction in the iron concentrations at the base of the euphotic zone. 
The simulations show that a decrease in iron concentration at the base of the euphotic zone shifts the phytoplankton community assemblage towards small algal forms (algal groups 1-3) and algal group 5 (Section 3bi) and that the primary production of algal groups 2, 3 , and 4 decreases. Algal group 4 experiences a large decrease in primary production for reduced iron conditions. Algal groups 1-3 adapt better to low iron concentrations in the simulations, which is consistent with observations that indicate that these groups are more efficient at iron uptake under low iron conditions compared to the larger algal groups (Sunda and Huntsman, 1995, 1997). The primary production of algal group 1 showed a $9 \%$ increase under low iron concentration conditions, because the decrease in pigment concentrations in the mixed layer due to reduction in biomass of the other algal groups resulted in increased downwelling irradiance. Also, the nutrient concentrations are higher and grazing pressure is lower below the mixed layer and algal group 1 can take advantage of these conditions. The increase in algal group 5 is due to the decrease in high mesozooplankton grazing. This may not be realistic because mesozooplankton biomass was overestimated in the model (Salihoglu and Hofmann, 2007, Section 4).

There is no evidence that climate change can increase iron concentrations in the deep ocean. Wells et al. (1999) reported that in the geological past tectonic processes could have an influence on periodic iron inputs into the eastern equatorial Pacific Ocean. Cycles of plankton productivity recorded in eastern equatorial Pacific sediments may therefore reflect the influence of tectonic processes superimposed on the effects of global climate forcing. The simulations show that increasing iron at the base of the euphotic zone $(120 \mathrm{~m})$ can result in increased primary production and carbon flux (33\%) even when there is no change in environmental conditions (e.g., vertical velocities). Increasing iron at $120 \mathrm{~m}$ without changing the vertical advection results in an increase in primary production during upwelling periods only, indicating that phytoplankton at $0 \mathrm{~N}, 140 \mathrm{~W}$ are strongly iron limited even during upwelling periods.

An increase in iron concentrations at the bottom of the euphotic zone shifts the phytoplankton community assemblage towards algal group 4 (Section 3bi, Fig. 2). This is consistent with the results of iron enrichment experiments (Landry et al., 2000a) which show that iron fertilization produces only a small increase in the biomass of Prochlorococcus spp. and Synechococcus and a large increase in the biomass of autotrophic eukaryotes. Landry et al. (2000a) also suggested that the relative constancy of the smaller-size forms might be the effect of grazers. The simulation results support this suggestion and show that for increased iron conditions the primary production of algal groups 2 and 3 increases $\sim 10 \%$, but that the increase in biomass is insignificant (Fig. 2).

Increased iron concentration actually decreases the simulated primary production of algal group 5. The model structure is such that increased production of algal groups produces increases in mesozooplankton and hence increased grazing pressure which decreases production of this algal group 5. This is not consistent with results from iron enrichment experiments that show that microphytoplankton biomass increases with increased iron concentrations (Landry et al., 2000a). Although a subsequent study by Landry et al. (2000b) 
showed that the grazing rate of mesozooplankton can increase ( 3 fold) in response to iron enrichment, the standing stock of mesozooplankton is strongly controlled by predation, which is not included in the current model structure.

Siegenthaler and Sarmiento (1993) suggested that climate change might also influence the carbon export rate by causing a more rapid remineralization of organic particles. With the model structure used in this study, changes in water temperature also affect the remineralization rates of particulate matter and at $0 \mathrm{~N}, 140 \mathrm{~W}$ sustained growth of the algal groups depends on remineralized iron. The simulations show that a decrease of up to $40 \%$ in annual integrated primary production can occur in response to decreased remineralization (Fig. 3), which could be produced by reduced water temperatures. Potential temperature dependencies need to be included in carbon cycling and climate models developed for the equatorial Pacific.

Martin et al. $(1989,1990)$ hypothesized that the increase in carbon export due to aeolian iron input can result in the drawdown of atmospheric carbon dioxide. The simulations show that the absence of aeolian iron fluxes produces a $16 \%$ decrease in primary production and carbon export (Section 3bi). Considering relatively low aeolian iron input at 0N, $140 \mathrm{~W}$ (Duce and Tindale, 1991; Ginoux et al., 2001), this strong sensitivity of export carbon production demostrates the importance of atmospheric iron inputs on phytoplankton carbon production. Thus, this process needs further study and refinement and needs to be included in future carbon cycle models developed for the equatorial Pacific.

ii. Change in vertical advection. Climate change may result in shifts in the rate of upwelling to the surface ocean due to the projected changes in the degree of stratification (Sarmiento et al., 1998). The simulations that used vertical velocity time series with a modified magnitude showed that decreased vertical velocities resulted in decreased iron input which produced changes in algal group relative carbon production and abundance (Fig. 4).

Increased vertical velocity shifted the phytoplankton community towards the larger algal groups 4 and 5. Although the primary production of algal group 5 increased considerably, the biomass of this group showed an insignificant change, because the increased mesozooplankton grazing converts algal group 5 primary production to secondary production.

The main differences between the simulations obtained with modified iron concentrations and modified vertical velocities is seen in the response of the annual integrated biomass, primary production, and carbon export. Changes in biomass are correlated with increased or decreased vertical velocities (Fig. 4). However, the general linear relation between primary production and carbon flux does not hold for these conditions. The simulated export carbon flux and primary production are similar for reduced vertical velocities. However, the export carbon flux shows a modest response (15\% increase) to increased vertical velocities; whereas, the primary production response is about double (32\%) this value (Fig. 4). Vertical velocities not only affect the amount of nutrients injected into the surface water, but also influence the sinking velocities of particulate materials (Salihoglu and Hofmann, 2007, Section 3). Increased vertical velocities decrease sinking of particles during upwelling times (positive vertical velocity), which generally corresponds to high carbon production. When 
the sinking speed of particles decreases, this results in enhanced remineralization of carbon and other nutrients, thus decreasing particulate material and enhancing carbon production as a feedback loop. The effect of the increase in sinking velocities during downwelling (negative vertical velocity) periods is relatively weaker, because these periods correspond to low carbon production.

Deepening of the thermocline, which reduces the vertical velocities in the model (Salihoglu and Hofmann, 2007, Section 2), results in decreases in simulated annual primary production and carbon export. However, the decrease in carbon export is higher than the decrease in primary production (Fig. 4). This suggests that a decrease in vertical velocities would diminish the carbon export at a higher rate than it reduces the carbon production.

\section{Summary and Conclusions}

This study showed that the simulated primary production is most sensitive to the variations in the thermocline depth as it is closely linked to the mixed layer depth and to the amount of iron at the base of the euphotic zone. The shoaling of the thermocline induces upwelling in the model and an increase in vertical advection shifts the system towards larger algal groups (autotrophic eukaryotes and large diatoms). Model sensitivity studies show that, in general, there is a strong coupling between the change in carbon production and export. However, the effect of vertical advection on carbon production and export is different from other environmental factors due to its direct effect on particulate carbon sinking rates. High-frequency variability in vertical advection and temperature is an important mechanism driving the carbon export. Filtering out low frequency physical forcing (retaining the high frequency physical forcing) drives the system towards larger algal forms and results in a $30 \%$ increase in carbon production and export. This variability in the simulated annual carbon production caused by TIWs and IGWs has a strong influence on the carbon export from the surface waters. This result illustrates that using carbon cycle models coupled with Ocean Global Circulation Models, which are currently incapable of resolving high frequency events, would result in unrealistic estimations of variability in carbon export from the surface waters.

All algal groups have a considerable effect on simulated phytoplankton carbon biomass, but not all have a strong effect on primary production and carbon export. This indicates that it may not be necessary to represent a broad spectrum of algal groups in carbon cycle models, because a few key groups appear to have a large influence on primary production and export variability. Combining algal groups 1-3 (low-light adapted Prochlorococcus, high-light adapted Prochlorococcus and Synechococcus) as a cyanobacteria group and retaining algal groups 4 and 5 as distinct groups may be sufficient for modeling large-scale carbon export from equatorial Pacific waters.

Grazing is the principal control on simulated algal biomass and that primary production and carbon export are mainly driven by iron availability at $0 \mathrm{~N}, 140 \mathrm{~W}$. The inability of Prochlorococcus spp. to use nitrate has a considerable effect on simulated primary 
production and carbon fluxes which can lead to nitrogen limitation even in the HNLC regions. The explanation for the relative constancy of these small ammonium-dependent species, which is now attributed only to grazing pressure, should be extended to include both nitrogen limitation and grazing constraints.

This study showed that recycled iron is an important component of the ecosystem dynamics. Sustained growth of algal groups depends on remineralized iron which accounts for $40 \%$ of the annual primary production in the Cold Tongue region.

Acknowledgments. This work would not have been possible without the hard work of the many scientists involved in the collection of the U.S. JGOFS EqPac data sets used in this study. We would also like to thank the TAO Project Office, Dr. Michael McPhaden, Director, for the use of the extensive data available from their mooring array. Thanks to Dr. Paul Ginoux for his atmospheric dust model output. Drs. Antonio Busalacchi, James Christian, Marjy Friedrichs, John Klinck, Raghu Murtugudde, Larry Atkinson and Véronique Garçon provided helpful comments on earlier presentations of this research. This research was generously supported by the National Aeronautics and Space Administration contracts NCC-5-258 and NAG5-11259. The computer facilities and resources were provided by the Commonwealth Center for Coastal Physical Oceanography at Old Dominion University, VA.

\section{REFERENCES}

Armstrong, R. A. 1994. Grazing limitation and nutrient limitation in marine ecosystems: Steady state solutions of an ecosystem model with multiple food chains. Limnol. Oceanogr., 39, 597-608.

Barber, R. T., M. P. Sanderson, S. T. Lindley, F. Chai, J. Newton, C. C. Trees, D. G. Foley and F. P. Chavez. 1996. Primary productivity and its regulation in the equatorial Pacific during and following the 1991-1992 El Niño. Deep-Sea Res. II, 43, 933-969.

Behrenfeld, M. J., A. J. Bale, Z. S. Kolber, J. Aiken and P. G. Falkowski. 1996. Confirmation of iron limitation of phytoplankton photosynthesis in the equatorial Pacific Ocean. Nature, 383, 508-511. Bidigare, R. R. and M. E. Ondrusek. 1996. Spatial and temporal variability of phytoplankton pigment distributions in the central equatorial Pacific Ocean. Deep-Sea Res. II, 43, 809-833.

Bissett, W. P., J. J. Walsh, D. A. Dieterle and K. L. Carder. 1999a. Carbon cycling in the upper waters of the Sargasso Sea: I. Numerical simulation of differential carbon and nitrogen fluxes. Deep-Sea Res. I, 46, 205-269.

. 1999b. Carbon cycling in the upper waters of the Sargasso Sea: II. Numerical simulation of apparent and inherent optical properties. Deep-Sea Res. I, 46, 271-317.

Bruland, K. W., K. J. Orians and J. P. Cowen. 1994. Reactive trace metals in the stratified central north Pacific. Geochim. Cosmochim. Acta, 58, 3171-3182.

Chavez, F. P. 1989. Size distribution of phytoplankton in the central and eastern Pacific Ocean. Global Biogeochem. Cycles, 3, 27-35.

Chavez, F. P., K. R. Buck, S. K. Service, J. Newton and R. T. Barber. 1996. Phytoplankton variability in the eastern and central Tropical Pacific. Deep-Sea Res. II, 43, 809-833.

Chavez, F. P., P. G. Strutton, G. E. Friedrich, R. A. Feely, G. C. Feldman, D. G. Foley and M. J. McPhaden. 1999. Biological and chemical response of the equatorial Pacific Ocean to the 1997-98 El Niño. Science, 286, 2126-2131.

Chavez, F. P., P. G. Strutton and M. J. McPhaden. 1998. Biological-physical coupling in the central equatorial Pacific during the onset of the 1997-98 El Niño. Geophys. Res. Let., 25, 3543-3546.

Coale, K. H., S. E. Fitzwater, R. M. Gordon, K. S. Johnson and R. T. Barber. 1996b. Control of community growth and export production by upwelled iron in the equatorial Pacific Ocean. Nature, $\underline{379,621-624 .}$ 
Coale, K. H. et al. 1996a. A massive phytoplankton bloom induced by an ecosystem-scale iron fertilization experiment in the equatorial Pacific Ocean. Nature, 383, 495-501.

Cullen, J. J., M. R. Lewis, C. O. Davis and R. T. Barber. 1992. Photosynthetic characteristics and estimated growth rates indicate grazing is the proximate control of primary production in the equatorial Pacific. J. Geophys. Res., 97, 639-654.

Dam, H. G., X. Zhang, M. Butler and M. R. Roman. 1995. Mesozooplankton grazing and metabolism at the equator in the central Pacific: Implications for carbon and nitrogen fluxes. Deep-Sea Res. II, 42, 735-756.

Doney, S. C. 1999. Major challenges confronting marine biogeochemical modeling. Global Biogeochem. Cycles, 13, 705-714.

Duce, R. A. and N. W. Tindale. 1991. Atmospheric transport of iron and its deposition in the ocean. Limnol. Oceanogr., 36, 1715-1726.

Dugdale, R. C. and F. P. Wilkerson. 1998. Silicate regulation of new production in the equatorial Pacific upwelling. Nature, 391, 270-273.

Fennel, K., M. R. Abbott, Y. H. Spitz, J. G. Richman and D. M. Nelson. 2003. Modeling controls of phytoplankton production in the southwest Pacific sector of the Southern Ocean. Deep-Sea Res. II, 50, 769-798.

Friedrichs, M. A. M. and E. E. Hofmann. 2001. Physical control of biological processes in the central equatorial Pacific Ocean. Deep-Sea Res. I, 48, 1023-1069.

Fung, I. Y., S. K. Meyn, I. Tegen, S. C. Doney, J. G. John and J. K. B. Bishop. 2000. Iron supply and demand in the upper ocean. Global Biogeochem. Cycles, 14, 281-295.

Geider, R. J., H. L. MacIntyre and T. M. Kana. 1998. A dynamic regulatory model of phytoplanktonic acclimation to light, nutrients, and temperature. Limnol. Oceanogr., 43, 679-694.

Ginoux, P., M. Chin, I. Tegen, J. Prospero, B. Holben, O. Dubovik and S. J. Lin. 2001. Sources and distributions of dust aerosols simulated with the GOCART model. J. Geophys. Res., 106, 20,225-20,273.

Gregg, W. W. and K. L. Carder. 1990. A simple spectral solar irradiance model for cloudless maritime atmospheres. Limnol. Oceanogr., 35, 1657-1675.

Hansen, D. V. 1990. Physical aspects of the El Niño event of 1982-1983, in Global Ecological Consequences of the 1982-1983 El Niño-Southern Oscillation, P. Glenn, ed., Elsevier, Amsterdam, 563 pp.

Higgins, H. W. and D. J. Mackey. 2000. Algal class abundances, estimated from chlorophyll and carotenoid pigments, in the western equatorial Pacific under El Niño and non-El Niño conditions. Deep-Sea Res. I, 47, 1461-1483.

Hutchins, D. A., G. R. DiTullio and K. W. Bruland. 1993. Iron and regenerated production: Evidence for biological iron recycling in two marine environments. Limnol. Oceanogr., 38, 1242-1255.

Iriarte, J. L. and G. A. Fryxell. 1995. Microphytoplankton at the equatorial Pacific (140W) during the JGOFS EqPac Time Series studies: March to April and October 1992. Deep-Sea Res. II, 42, 559-583.

Jickells, T. and L. Spokes. 2002. Atmospheric iron inputs to the oceans, in Biogeochemistry of Iron in Seawater, D. Turner and K. Hunter, eds., Wiley, NY.

Johnson, K. S., R. M. Gordon and K. H. Coale. 1997. What controls dissolved iron concentrations in the World Ocean? Mar. Chem., 57, 137-161.

Kessler, W. S., M. McPhaden and K. M. Weickmann. 1995. Forcing of intraseasonal Kelvin waves in the equatorial Pacific. J. Geophys. Res., 100, 10,613-10,631.

Klein, P. and J. H. Steele. 1985. Some physical factors affecting ecosystems. J. Mar. Res., 43, 337-350.

Landry, M. R., J. Kirshtein and J. Constantinou. 1995. A refined dilution technique for measuring the community grazing impact of microzooplankton, with experimental tests in the central equatorial Pacific. Mar. Ecol. Prog. Ser., 120, 53-63. 
1996. Abundances and distributions of picoplankton populations in the central equatorial Pacific from $12 \mathrm{~N}$ to $12 \mathrm{~S}, 140 \mathrm{~W}$. Deep-Sea Res. II, 43, 871-890.

Landry, M. R., J. Constantinou, M. Latasa, S. L. Brown, R. R. Bidigare and M. E. Ondrusek. $2000 \mathrm{~b}$. Biological response to iron fertilization in the eastern equatorial Pacific (IronEx II). 3. Dynamics of phytoplankton growth and microzooplankton grazing. Mar. Ecol. Prog. Ser., 201, 57-72.

Landry, M. R., M. E. Ondrusek, S. J. Tanner, S. L. Brown, J. Constantinou, R. R. Bidigare, K. H. Coale and S. Fitzwater. 2000a. Biological response to iron fertilization in the eastern equatorial Pacific (IronEx II). 1. Microplankton community abundances and biomass. Mar. Ecol. Prog. Ser., 201, 17-42.

Landry, M. R. et al. 1997. Iron and grazing constraints on primary production in the central equatorial Pacific: An EqPac synthesis. Limnol. Oceanogr., 42, 405-418.

Latasa, M., M. R. Landry, L. Schlueter and R. R. Bidigare. 1997. Pigment-specific growth and grazing rates of phytoplankton in the central equatorial Pacific. Limnol. Oceanogr., 42, 289-298.

Laws, E. A., P. G. Falkowski, W. O. Smith, H. Ducklow and J. J. McCarthy. 2000. Temperature effects on export production in the open ocean. Global Biogeochem. Cycles, 14, 1231-1246.

Le Borgne, R., R. A. Feely and D. J. Mackey. 2002. Carbon fluxes in the equatorial Pacific: A synthesis of the JGOFS programme. Deep-Sea Res. II, 49, 2425-2442.

Lindley, S. T., R. R. Bidigare and R. T. Barber. 1995. Phytoplankton photosynthesis parameters along 140W in the equatorial Pacific Deep-Sea Res. II, 42, 441-463.

Martin, J. H., W. W. Broenkow, S. E. Fitzwater and R. M. Gordon. 1990. Yes, it does: A reply to the comment by Banse. Limnol. Oceanogr., 35, 775-777.

Martin, J. H. et al. 1994. Testing the iron hypothesis in ecosystems of the equatorial Pacific Ocean. Nature, 371, 123-129.

Martin, J. H., R. M. Gordon and S. E. Fitzwater. 1991. The case for iron. Limnol. Oceanogr., 36, 1793-1802.

Martin, J. H., R. M. Gordon, S. Fitzwater and W. W. Broenkow. 1989. VERTEX: phytoplankton/iron studies in the Gulf of Alaska. Deep-Sea Res. I, 36, 649-680.

Moore, J. K., S. C. Doney, J. A. Kleypas, D. M. Glover and I. Y. Fung. 2002a. An intermediate complexity marine ecosystem model for the global domain. Deep-Sea Res. II, 49, 403-462.

Morel, F. M., R. J. M. Hudson and N. M. Price. 1991. Limitation of productivity by trace metals in the sea. Limnol. Oceanogr., 36, 1742-1755.

Nelson, D. M., P. Treguer, M. A. Brzezinski, A. Leynaert and B. Queaguiner. 1995. Production and dissolution of biogenic silica in the ocean: Revised global estimates, comparison with regional data and relationship to biogenic sedimentation. Global Biogeochem. Cycles, 9, 359-372.

Philander, G. 1990. El Niño, La Niña, and the Southern Oscillation, Academic Press, Inc., Princeton, NJ, 293 pp.

Picaut, J., E. Hackert, A. J. Busalacchi, R. Murtugudde and G. S. E. Lagerloef. 2002. Mechanisms of the 1997-1998 El Niño-La Niña, as inferred from space-based observations. J. Geophys. Res., 107, 1-20.

Price, N. M., B. A. Ahner and F. M. M. Morel. 1994. The equatorial Pacific Ocean: Grazer-controlled phytoplankton populations in an iron-limited ecosystem. Limnol. Oceanogr., 39, 520-534.

Qiao, L. and R. H. Weisberg. 1995. Tropical instability wave kinematics: Observations from the tropical instability wave experiment. J. Geophys. Res., 100, 8677-8693.

Rue, E. L. and K. W. Bruland. 1995. Complexation of iron(III) by natural organic ligands in the central north Pacific as determined by a new competitive ligand equilibration/adsorptive cathodic stripping voltammetric method. Mar. Chem., 50, 117-138.

1997. The role of organic complexation on ambient iron chemistry in the equatorial Pacific Ocean and the response of a mesoscale iron addition experiment. Limnol. Oceanogr., 42, 901-910. 
Salihoglu, B. 2005. Modeling the effects of physical and biogeochemical processes on phytoplankton species and carbon production in the equatorial Pacific Ocean, Ph.D. thesis, Old Dominion University, 193 pp.

Salihoglu, B. and E. E. Hofmann. 2007. Simulations of phytoplankton species and carbon production in the equatorial Pacific Ocean 1. Model configuration and ecosystem dynamics. J. Mar. Res., 65, 219-273.

Sarmiento, J. L., T. M. C. Hughes, R. J. Stouffer and S. Manabe. 1998. Simulated response of the ocean carbon cycle to anthropogenic climate warming. Nature, 393, 245-249.

Sarmiento, J. L. et al. 2004. Response of ocean ecosystems to climate warming. Global Biogeochem. Cycles, 18, art. GB3003.

Siegenthaler, U. and J. L. Sarmiento. 1993. Atmospheric carbon dioxide and the ocean. Nature, 365, $119-125$.

Strutton, P. G. and F. P. Chavez. 2000. Primary productivity in the equatorial Pacific during the 1997-98 El Niño. J. Geophys. Res., 105, 26,089-26,101.

Sunda, W. G. and S. A. Huntsman. 1995. Iron uptake and growth limitation in oceanic and coastal phytoplankton. Mar. Chem., 50, 189-206.

. 1997. Interrelated influence of iron, light and cell size on marine phytoplankton growth. Nature, 390, 389-392.

Takahashi, T., R. A. Feely, R. Weiss, R. H. Wanninkhof, D. W. Chipman, S. C. Sutherland and T. T. Takahashi. 1997. Global air-sea flux of $\mathrm{CO}_{2}$ : an estimate based on measurements of sea-air $\mathrm{pCO}_{2}$ difference. Proc. National Acad. Sci., 94, 8292-8299.

Takeda, S. 1998. Influence of iron availability, on nutrient consumption ratio of diatoms in oceanic waters. Nature, 393, 774-777.

Van den Berg, C. M. G. 1995. Evidence for organic complexation of iron in seawater. Mar. Chem., 50, 139-157.

Verity, P. G., D. K. Stoecker, M. E. Sieracki and J. R. Nelson. 1996. Microzooplankton grazing of primary production at $140 \mathrm{~W}$ in the equatorial Pacific. Deep-Sea Res. II, 43, 1227-1256.

Walsh, J. J. 1976. Herbivory as a factor in patterns of nutrient utilization in the sea. Limnol. Oceanogr., 21, 1-13.

Wells, M. L., N. M. Price and K. W. Bruland. 1995. Iron chemistry in seawater and its relationship to phytoplankton: A workshop report, Mar. Chem., 48, 157-182.

Wells, M. L., G. K. Vallis and E. A. Silver. 1999. Influence of tectonic processes in Papua New Guinea on past productivity in the eastern equatorial Pacific Ocean. Nature, 398, 601-604.

Wunsch, C. and A. E. Gill. 1976. Observations of equatorially trapped waves in Pacific sea level variations. Deep-Sea Res., 23, 371-390.

Wyrtki, K. 1975. El Niño - the dynamic response of the equatorial Pacific Ocean to atmospheric forcing. J. Phys. Oceanogr., 5, 572-584.

- 1985. Water displacements in the Pacific and the genesis of El Niño cycles. J. Geophys. Res., 90, 7129-7132.

Yu, Z., J. P. J. McCreary and J. A. Proehl. 1995. Meridional asymmetry and energetics of tropical instability waves. J. Phys. Oceanogr., 25, 2997-3007.

Zhang, X., H. G. Dam, J. R. White and M. R. Roman. 1995. Latitudinal variations in mesozooplankton grazing and metabolism in the central tropical Pacific during the U.S. JGOFS EqPac study. DeepSea Res. II, 42, 695-714.

Received: 18 May, 2006; revised: 25 January, 2007. 